QUADERNS DE FILOSOFIA VOL. IV NÚM. 2 (20I7): I I-34

eISSN: 234I-3042 DOI: I 0.7203/QFIA.4.2.8I94

María Medina-Vicent ${ }^{1}$

Universitat Jaume I, Castelló

\title{
Exigencias éticas del prosumidor-ciudadano frente a las empresas ${ }^{2}$
}

Ethical requirements of the prosumer-citizen facing companies

Recibido: 28/4/16. Aceptado: 28/2/17

Resumen: Los procesos de recesión económica y los cambios políticos que se están desarrollando en las sociedades occidentales, plantean una disyuntiva sobre el papel social de las empresas y su modo de relacionarse con el público. Se ha producido el despertar de consumidores/as conscientes de su poder, tanto como creadores/as de contenidos a través de los espacios digitales, como de vigilantes activos de las acciones de empresas y gobiernos. Ante esta realidad, las organizaciones no pueden actuar sin atender al entorno, deben reconocer su responsabilidad social y responder a las demandas de sus stakeholders a través de una gestión empresarial ética y comunicativa. En el presente artículo se reflexiona en torno a una propuesta de ética empresarial de corte discursivo capaz de responder a las exigencias sociales y promover una comunicación transparente que incorpore los intereses de los grupos afectados por la actividad empresarial.

Abstract: The economic crisis and the political changes that are taking place in Western societies set out a dilemma about the social role of companies and their social interactions. Nowadays, consumers have become aware of their power, both as creators of content through digital tools, as active guards of the actions of companies and governments. In front of this, organizations cannot act without pay

${ }^{1}$ Per a contactar amb l'autora: medinam@uji.es

${ }^{2}$ Este trabajo se inscribe en el Proyecto de Investigación Científica y Desarrollo Tecnológico del Plan de Promoción de la Investigación de la Universitat Jaume I para el año 2016, titulado "El potencial de las éticas aplicadas en las herramientas de participación del Gobierno Abierto y la Sociedad Civil” (Referencia: UJI-A2016-04). 
attention to their environment; companies must recognize their social responsibility and respond to the stakeholders demands through an ethical and communicative management. We'll explain a business ethics based on a discursive model, because it can be useful to attend social demands, to promote transparent communication, and to incorporate the interests of those affected by business activity.

Palabras clave: ética empresarial, ética discursiva, prosumidor/a, monitorización, confianza.

Keywords: business ethics, discourse ethics, prosumer, monitoring, trust.

\section{INTRODUCCIÓN}

$\mathrm{L}$ AS EMPRESAS Son organismos vivos que se relacionan con el entorno a través de sus acciones y sus comunicaciones. La crisis económica que se viene desarrollando desde el año 2007, así como el consecuente descrédito de los gobiernos debido entre otras cosas a sus políticas austeras, son el caldo de cultivo para el resurgir de la ciudadanía (FeEnstra et al. 2016). Ahora más que nunca se pone de relieve que una gestión ética y saludable de las empresas resulta vital para el mantenimiento de su actividad, y para conseguir este objetivo, su devenir diario debe estar en conexión con las demandas cambiantes del entorno.

En este sentido, la confianza es un activo clave, ya que cuando se confía en otra persona se depositan ciertas expectativas en su comportamiento, al igual que ocurre con las organizaciones. Por esta razón, la coherencia y la credibilidad son dos aspectos clave de los discursos comunicativos a través de los cuales se va a construir la imagen de la empresa en el imaginario social. Así, se debe tener en cuenta que debido a los cambios acontecidos en el escenario actual, "el ciudadano se siente más amenazado por las maquinarias comunicativas de instituciones públicas y grandes corporaciones" (Álvaro 20I3, 225). Frente al descontento, la desconfianza e incluso la desafección ciudadana, las organizaciones tendrán que aprender a incorporar la ética en su gestión y a comunicarla. En este orden de cosas, uno de los rasgos clave de esta nueva realidad es que "el comportamiento del consumidor, pero también el de las empresas, poco tiene que ver con el que tenían hace unas décadas" (MEdinAAguerrebere 2013, 95).

El principal objeto del presente texto se centra en reconstruir las bases morales de la ética aplicada a la empresa, entendida como la respuesta más adecuada a la crisis de confianza social que viven gran parte de dichas organizaciones. Además, se ahondará en los nuevos rasgos que caracterizan a los/as consumidores/as conscientes de su papel como ciudadanos/as, y de su 
capacidad para la producción de contenidos, rasgos que les convierte en sujetos audaces frente a los mensajes de las empresas. Esta nueva realidad transforma las relaciones existentes entre las instituciones y sus públicos, que tradicionalmente han estado caracterizadas por la unidireccionalidad, otorgándoles un nuevo carácter bidireccional y permitiendo la entrada de muy diversas voces en la empresa, una situación que solamente se puede construir desde la confianza.

Así pues, reflexionar sobre la dimensión moral de las organizaciones empresariales y la necesaria incorporación de la ética en su gestión y comunicación, supone reconocer a las empresas como parte de la sociedad civil, de un espacio de libertad que las dota de moralidad. Para esto, la autora se basará en la propuesta de ética empresarial y económica dialógica fundamentada en la ética discusiva de J. Habermas y K. O. Apel (Cortina 2003; García-Marzá 2004; Conill 2006). Esta metodología resulta interesante, ya que exige la consecución de un acuerdo de todas las partes implicadas a través de argumentos esgrimidos sin ningún tipo de coacción en el seno de un diálogo real inclusivo.

\section{LA CONSTRUCCIÓN DE ORGANIZACIONES SALUDABLES}

Señala la filósofa Adela Cortina que ahora más que nunca necesitamos la ética (CoRTina 2013), y es que ha sido ampliamente demostrado que los malos hábitos y vacíos éticos existentes a la hora de gestionar empresas y gobiernos, han provocado grandes costes humanos, que hoy en día aún se están pagando en nuestro país. La toma de conciencia de la ciudadanía de dicha situación, ha puesto en el punto de mira a empresas, gobiernos y otras entidades. Frente a este descrédito, las organizaciones no pueden renegar más de su responsabilidad social y tienen que replantear tanto su gestión como su comunicación. Es decir, en un contexto de crisis económica y social, con una desafección ciudadana generalizada, existe la necesidad de incorporar una gestión ética en el día a día de las organizaciones empresariales. Porque solamente desde la ética, las empresas podrán recuperar la confianza perdida por parte de la sociedad así como atender a las nuevas exigencias y necesidades del consumidor/a, que también es ciudadano/a y tiene el poder de crear contenidos propios (prosumidor/a). Y lo más importante, porque ninguna campaña de comunicación llevada a cabo por una marca o empresa tendrá éxito, si la propia organización no goza de legitimidad y credibilidad social. Consecuentemente, la ética es el camino a seguir para recuperar el valor social de las empresas y para comunicar de forma veraz y digna sus actuaciones y decisiones. De cualquier otro modo, el público no otorgará crédito a la empresa y dejará de prestarle su apoyo, lo que implicaría a la larga, acabar con el desarrollo de su actividad concreta. 
En el presente punto, se definirá un modelo de gestión ética económica y empresarial basada en la ética dialógica habermasiana, desarrollada por la Escuela de Valencia, ya que las bases morales que brinda pueden suponer el modo más acertado para que las empresas se comprometan con su fin social: "satisfacer necesidades humanas con calidad, a través de la obtención del beneficio" (Cortina I997, 29). Dicho modelo aporta las bases morales de funcionamiento para una gestión empresarial respetuosa con el entorno, que promueva la escucha activa de los diferentes grupos de intereses, y convierta la igualdad y la justicia en valores irrenunciables de la cultura corporativa. Porque éste es el único modo de promover una comunicación transparente de las dinámicas organizacionales.

\section{1 Ética empresarial de corte discursivo}

Nos encontramos insertos en un mundo global y globalizado, una realidad social caracterizada por la transfiguración de los límites espacio-temporales. En este escenario de interconexiones, las TICs juegan un papel central, permitiendo el acceso masivo de la ciudadanía a los contenidos informativos, generando "nuevos espacios de interacción" (Querol 20 I I, 29). Al mismo tiempo, los entornos económicos se vuelven inestables, obligando a las empresas a internacionalizarse, ampliando así sus ámbitos de acción. Este hecho implica que sus decisiones ya no afectan tan solo a su entorno más inmediato, sino a todos los territorios en los que radica su actividad. La interconexión propia de esta sociedad global acrecienta las responsabilidades de la empresa, que tiene que lidiar con mayor número de grupos, ahora en diferentes Estados nacionales. De este modo, al operar de forma simultánea en escenarios con cuerpos legislativos y tradiciones diferentes, la ética se convierte en la herramienta idónea para ofrecer soluciones a los conflictos de acción que le puedan surgir en los diferentes contextos, ya que plantea una forma de universalizar las buenas acciones más allá de los marcos legales. Y es que "cuanto más complejas son las sociedades y más cambiantes los entornos, más ineficaces resultan las soluciones jurídicas y más rentables los mecanismos éticos para resolver los conflictos con justicia” (Cortina 2003, 29). En resumen, la globalización modifica los límites de la esfera económica, política y tecnológica; distorsionando las fronteras nacionales y convirtiendo la dimensión moral en la clave de adaptación empresarial a esta nueva realidad.

La ética empresarial que se propone aquí tiene carácter integrativo, es decir, entiende "economía y ética como dos lógicas interconectadas en el ámbito social” (GARCíA-MARZÁ 2004, 124). Desde esta concepción se deja atrás la visión tradicional de la empresa como un ente aislado y "la economía sus- 
tentada sobre la racionalidad autointeresada e individualista del homo oeconomicus" (CAlvo 2013, 67), para empezar a reconocer a la empresa como una entidad plural, que tiene responsabilidad sobre sus decisiones y acciones. Pero no solamente esto, sino que ante el retroceso en el papel del Estado, y el nuevo protagonismo de la sociedad civil, la empresa se reconoce como un ente moral que se mueve en el ámbito de la libertad, en la moralidad de sus decisiones, ya que tiene la capacidad de escoger entre un curso de acción u otro, al igual que lo hacemos los seres humanos. Una vez reconocido el carácter moral de las organizaciones empresariales, se propone una ética empresarial y económica dialógica fundamentada en la ética discusiva desarrollada por Jürgen Habermas y Karl Otto Apel, ya que se basa en el principio de universalización, por el cual "el punto de vista moral se centra en el reconocimiento recíproco de todos los implicados por los efectos de una norma o institución" (GARCíA-Marzí 2004, 103), y exige la consecución de un acuerdo de todas las partes implicadas a través de un diálogo real inclusivo. Desde este punto de vista, cualquier norma o acción llevada a cabo por la empresa, deberá ser discutida en un diálogo igualitario que incluya las voces afectadas por ésta.

A partir de esta concepción, las bases sobre las que ha de desarrollarse la actividad empresarial son la legitimidad y la confianza que ha de serles otorgada por parte de la ciudadanía. Y esto pasa por la gestión transparente de sus recursos morales, que son "todas aquellas disposiciones y capacidades que nos conducen al entendimiento mutuo, al diálogo y al acuerdo como mecanismos básicos para la satisfacción de intereses y para la relación consensual de los conflictos de acción" (García-Marzí 2004, 47). De este modo, la validez de la empresa debe residir en la gestión comunicativa de sus recursos morales y no en una mera estrategia racionalizadora, que es lo que ha generado una total desconfianza de los/as consumidores/as frente a las marcas, y un descrédito enorme de las comunicaciones y campañas que estas empresas llevan a cabo a través de diferentes medios. Al contrario, la gestión comunicativa de estos, le permite ser responsable de sus acciones, basadas en juicios racionales, y reconocer que los intereses de los demás deben ser integrados en la práctica empresarial, hecho que le permitirá comprometerse con el cumplimiento de las expectativas que el público tiene depositadas en dichas instituciones.

Y qué es comprometerse más que establecer una relación de confianza entre la empresa y sus públicos. Una relación basada en un juego de expectativas recíprocas, que otorga a la organización la capacidad de justificar sus actos, aportando razones a aquellos grupos frente a los que debe responder. Consecuentemente, si la empresa quiere mantener su posición social, debe basar sus relaciones en la reciprocidad y el reconocimiento de la autonomía que ostentan los grupos con los que se encuentra entrelazada. En dicho re- 
conocimiento se hace patente la necesidad de fomentar diálogos reales que conviertan a la organización en un ente plural y abierto a las críticas. Porque al tener que dar razón de sus actuaciones la empresa debe establecer un diálogo edificado sobre razones morales, ya que esto le va a permitir argumentar de forma universalista, y en un contexto globalizado, enfrentarse exitosamente a los conflictos globales.

Un enfoque dialógico de la ética empresarial permite crear una ética universalista, porque a través del diálogo se pueden identificar los presupuestos morales universales referidos a la validez de las normas y a la inclusión en el diálogo de los grupos afectados por éstas. Si bien somos conscientes de que el contrario de esta afirmación también podría llegar a ser cierto, es decir, que la validez de las normas es interna a la comunidad que entabla el diálogo; consideramos que las normas universales exigirían un diálogo global, al menos en potencia. La utilidad que se desprende de dicha concepción permite afirmar que las normas vigentes en una sociedad no tienen por qué ser válidas, si no cuentan con todos los intereses en juego y expresan intereses generalizables. Esta afirmación entiende la empresa como una institución dinámica que debe adaptarse a los cambios culturales y de otra índole, hecho que construye el espacio para incorporar los cambios en las demandas de consumidores/as, que deberán tener vigencia y validez moral. Consiguientemente, la clave reside en reconocer el valor moral del diálogo, como un camino a través del cual "se alcanza el acuerdo y consenso necesarios para establecer, mantener y desarrollar la legitimidad de la empresa" (GARCía-Marzá 2004, 236), y dicha legitimidad debe encontrar sus bases, hoy en día, en pilares tan sólidos como la transparencia o el respeto al medioambiente.

En esta línea, se debe señalar que el principio del diálogo en búsqueda del acuerdo describe un contrato moral basado en la plena ausencia de coacción entre los participantes. Cuando habla de contrato moral, García-Marzá se refiere a un "acuerdo racional entre todas las partes implicadas y/o afectadas por la actividad empresarial” (GARCíA-MARZÁ 2004, 160). Este contrato permite recoger la reciprocidad, ya que a partir de él se reconoce el hecho de que existe un juego de expectativas recíprocas entre la empresa y sus grupos de intereses. Se trata pues de diálogos en los que existe la posibilidad de comunicación, donde están incluidos todos los afectados por la actividad empresarial, que deben poder participar recíprocamente y en igualdad de condiciones. No obstante, se debe resaltar que se trata de una idea regulativa, en la realidad no se van a dar nunca las condiciones ideales para el diálogo, aun así, se debe hacer lo posible por aproximarse a dichos principios.

Desde aquí, se considera que una comunicación ética puede ser uno de los caminos más adecuados para la recuperación de la confianza del públi- 
co, para afianzar los lazos entre empresa y sociedad, y sentar las bases para el desarrollo de dicho diálogo. Cuando se trata de comunicar éticamente, esto implica tener como valores centrales la transparencia, la veracidad, la reciprocidad y la escucha activa. Sin embargo, no falte decir que una empresa no podrá comunicar éticamente si en su gestión misma no incorpora la ética como principio guía. A colación, nuestras razones para optar por la ética discursiva como modelo para la consecución de una empresa ética y saludable se centran sobre todo en el proceso de participación dialógica que dicho modelo permite incorporar en la empresa. En este sentido, somos conscientes de que

...la cantidad de intereses en juego que rodean la organización hace necesario establecer un modelo participativo que permita incluir de manera activa tanto a sus stakeholders internos como externos. Un tipo de participación que posibilite el consenso y el acuerdo y cuya inclusión no esté supeditada a un determinado punto de vista moral, a una cultural o historia compartida, a una aportación de capital determinada o a una condición social o laboral concreta (CALVO 20 IOA, 276)

Esta metodología subraya la participación y contribuye a una conformación de empresas más conscientes y a la constitución de una ciudadanía más activa. En esta línea, hemos escogido esta opción frente a otras como la de la ISCT de Donaldson y Dunfee (I994), porque destacamos el potencial universal de la ética discursiva. Así pues, la ISCT adopta una postura pluralista que reconoce que las normas éticas no necesariamente son de aplicación universal (Alvarado et al. 2009) sino que debe existir tolerancia entre los enfoques de otras culturas, siempre evitando caer en el relativismo ético (Donaldson y DunfeE 1999). Si bien esta teoría tiene su potencial transformador, consideramos que hay marcos normativos universales que deben ser respetados y que aunque las organizaciones deben tener en cuenta la cultura de cada territorio en el que operan, existen principios morales universales que deben primar. Desde nuestro punto de vista, en la intersección entre lo universal y lo particular se crea un espacio donde puede operar de forma efectiva la propuesta de la ética discursiva, que permitirá a la organización discernir qué normas son las que debe respetar atendiendo a las exigencias de los stakeholders que operen en cada territorio.

\subsection{Stakeholders: la escucha activa del entorno}

Esta pequeńa aproximación a la ética empresarial dialógica nos ha permitido observar algunas de las potencialidades de dicho modelo para construir 
organizaciones saludables y sociedades justas. La clave se centra en reconocer la relación recíproca entre organización y stakeholders, quienes deben ser incluidos en un diálogo real desarrollado sin coacciones. Es la Teoría de los stakeholders (FREEMAN 1984) la que permite tender un puente entre la teoría y la práctica, aproximándonos al diálogo mediante la identificación de los grupos de intereses de la empresa, proceso en el cual una buena gestión de la comunicación corporativa resulta imprescindible. Dicha teoría entiende los stakeholders como "any group or individual who can affect, or is affected by, the achievement of a corporation's purpose. Stakeholders include employees, customers, suppliers, stockholders, banks, environmentalists, government and other groups who can help or hurt the corporation" (FreEman 1984, vi). De tal suerte, resulta interesante señalar que dicho término fue utilizado por primera vez en un memorando sobre planificación empresarial elaborado por el Stanford Research Institute en el año 1963, donde se definía los stakeholders como aquellos grupos sin cuyo apoyo la organización podría dejar de existir. Como se puede observar, esta definición implica el reconocimiento por parte de la empresa de una necesidad de relacionarse con la sociedad. Se deja así atrás una concepción de racionalidad económica que concibe a la empresa como un ente autista desvinculado de lo social.

Freeman desarrolla la teoría de los stakeholders a lo largo de la década de los ochenta, y uno de sus rasgos fundamentales es que concibe un modelo de gestión que integra siempre de forma conjunta los aspectos éticos y los organizativos de la empresa (GonzÁlez Esteban 20 i2, 71). Dicho autor no es el primero en hablar de la interrelación de la empresa con sus públicos, pero sí el primero en poner de relieve la necesidad de gestionar la empresa desde dicha interrelación. En consecuencia, la teoría de los stakeholders tiene como novedad la inclusión de componentes económicos y éticos en un mismo paquete, donde se hace especial énfasis en las relaciones de la empresa con el entorno. Desde un punto de vista moral, el ámbito de las relaciones es lo que resulta de mayor interés, ya que se empieza a hacer patente la importancia de incluir en la gestión empresarial los intereses de aquellos grupos con los que se relaciona la empresa en el desarrollo de su actividad. Así, se reconoce la pluralidad de intereses que se encuentran implicados en la empresa, la existencia de valores morales y una perspectiva a largo plazo del proyecto empresarial. Esto otorga el fundamento para poder desarrollar nuestra visión de la responsabilidad social empresarial, ya que para responder o dar razón de nuestras actuaciones, primero se tiene que saber ante quién. Así pues, la empresa deberá entablar un "diálogo con todos sus stakeholders, con el fin de averiguar qué intereses y valores son comunes a todos ellos y por tanto universalizables, qué intereses son propios de cada grupo y cuales son simplemente individuales" (GonZález Esteban y García- 
MARZÁ 2006, 162). De estos tres tipos de intereses, la empresa siempre deberá intentar satisfacer en primer lugar los universalizables. Aunque los grupales e individuales se sitúen por detrás, la organización también se esforzará por tenerlos en cuenta y darles respuesta.

Para mantener su actividad prolongada en el tiempo, la empresa deberá no solo identificar a estos grupos de intereses, sino también integrar sus demandas para darles respuesta, mientras mantiene siempre una actitud proactiva respecto a cada uno de ellos de forma jerarquizada. A lo largo del tiempo, la gestión comunicativa de sus recursos morales, entre los que se encuentra la confianza, le permitirá generar reputación en su público. En esta línea, hay que tener en cuenta que la responsabilidad social corporativa no es lo mismo que la reputación, "la RSC supone la asunción empresarial de la responsabilidad por su impacto social ... pero su reputación es la percepción que individuos, grupos y sociedad tienen de esa empresa, positiva, neutra o negativa en todos los contextos posibles" (DEL FresNo 20I2, 26). Al fin y al cabo, responsabilidad empresarial se refiere a la obligación moral que tienen las empresas de responder de sus propias actuaciones ante la sociedad, en la medida en que las empresas respondan ante sus grupos de forma veraz, podrán generar una mejor reputación.

En su ajustamiento a la sociedad, la empresa debe tener en cuenta la realidad y las características del entorno en que se mueve, en su justificación sobre las elecciones que ha tomado, deberá tener en cuenta tanto las normas vigentes en esa sociedad como las válidas moralmente. Porque la economía "es mucho más que lo que muchos entienden por economía, ya que ésta tiene que estar al servicio del desarrollo humano" (Cortina 2005, 11). Por esta razón, la empresa será responsable de todos sus ámbitos, tanto el económico y el ambiental como el social, de forma constantemente interrelacionada. Repasando lo que se ha venido señalando hasta el momento, cualquier organización en su toma de decisiones desde la libertad que caracteriza a todo ser o institución que se mueve dentro del ámbito de la sociedad civil, posee una responsabilidad de carácter económico, social y ecológico (GonzÁLEZ EsTEBAN 2007, 207). Es decir, debe dar respuesta de sus actos y actividades frente a la sociedad, sobre todo frente a aquellos afectados tanto presentes como futuros, porque está inserta en todos los espacios de la vida social y como tal, sus decisiones afectan las condiciones de vida de la ciudadanía.

\section{CAMbios EN LA Figura DEL/LA CONSUMidor/A}

Anteriormente, se ha destacado la necesidad de identificar los grupos de intereses o stakeholders que se encuentran directamente relacionados con la 
actividad empresarial para que dicha actividad goce de legitimidad social. El conjunto de consumidores y consumidoras forman parte de dichos grupos, pero hoy en día, no se debe pasar por alto el hecho de que tanto sus prácticas como sus exigencias han variado considerablemente. Aquí se destacarán dos rasgos que son de vital importancia para conocer a esta nueva figura de consumo y acción: su capacidad para crear contenidos a través de las redes y su capacidad crítica como ciudadano/a para desvelar las malas prácticas empresariales y/o de otra índole. Estos dos rasgos se pueden asociar a dos procesos culturales, políticos y económicos aún abiertos. En primer lugar, la sociedad de la información y las facilidades que otorgan las nuevas herramientas digitales para compartir, crear contenidos e influir en las empresas. En segundo lugar, la crisis económica y social que está azotando nuestro país, así como muchos otros, y que han despertado la conciencia crítica de la ciudadanía, que se muestra ahora alerta respecto a las prácticas de empresas, gobiernos y otras instituciones sociales.

\subsection{Prosumidores/as y creación de contenidos}

Se acepta de forma generalizada que el primer autor en acuñar el término prosumer fue Toffle en su obra The Third Wave (Toffler 1980), para referirse a aquel consumidor que se convierte en productor de contenidos, que al mismo tiempo acaba consumiendo. Cabe señalar que existen antecedentes a dicho concepto en los trabajos de McLuhan y Nevitt, quienes en su obra Take Today (McLuhan y NevitT, I972) avanzaron que la tecnología electrónica permitiría al consumidor asumir simultáneamente los roles de productor y consumidor. Esta idea se ha visto finalmente realizada, otorgándole al sujeto de consumo la capacidad de influir en los procesos empresariales y la configuración de la propia marca. De esta manera, el concepto "prosumidor", procedente del inglés prosumer, pretende enlazar dos palabras: producer (productor) y consumer (consumidor). Fusionando estas dos vertientes, se destaca el paso del público de un papel pasivo a otro activo y consciente de la importancia de su rol en la legitimidad de la empresa. Nada de esto sería posible sin el desarrollo de la web 2.0 y las redes sociales, que crean nuevos espacios de interacción entre consumidores/as y de creación de contenidos diversos

Much of what transpires online, especially on what has come to be known as Web 2.0, is generated by the user. Web 2.0 is contrasted to Web 1.0 (e.g. AOL, Yahoo), which was (and still is) provider- rather than user-generated. Web 2.0 is defined by the ability of users to produce content collaboratively, whereas most of what exists on Web 1.0 is provider-generated. It is on Web 2.0 that there has been a dramatic explosion in prosumption. It can be argued that Web 2.0 
should be seen as crucial in the development of the 'means of prosumption'; Web 2.0 facilitates the implosion of production and consumption (RITZER y JURGENSON 2OIO, 19)

Como punto de partida, se debe reconocer que "el mercado de la comunicación cuenta con nuevas audiencias que participan a la vez como productores y consumidores de contenidos a través de nuevas pantallas" (ANDrEUSÁnchez y Martín-PAscual 20I4, 136). Las nuevas pantallas se refieren a las oportunidades que otorga el escenario tecnológico para que ciudadanos/ as y consumidores/as influyan en las empresas o en los procesos políticos. La práctica de monitorización de la actividad política es un claro ejemplo del papel activo que toma el público, y esto no se puede obviar, ya que influye en los procesos de consumo, y en cómo la gente se relaciona con la empresa y las marcas. Así, "el proceso de monitorización supone, en los momentos que se produce, una evidente capacidad de influencia del ciudadano que ejerce la acción" (FeEnSTRa 2013 B, 159). En resumen, se han destacado dos rasgos, el interés y capacidad de crear contenidos y consumirlos, así como la capacidad de influir en los procesos económicos y políticos. Esta realidad promueve la reformulación de parte de la comunicación que lleva a cabo la empresa, que no puede actuar de espaldas al público, ya que sus acciones están siendo vigiladas a la vez que la veracidad de sus campańas de comunicación está en el punto de mira de la opinión pública. Por tanto, el conjunto de prosumidores/as se encuentra formado por sujetos que nada tienen que ver ya con seres pasivos y aislados, sino con otros dispuestos a participar en la construcción de la marca, influenciando incluso los modos en que se hace publicidad.

Desde el marco de las comunicaciones publicitarias también se ha explorado el importante papel que pueden desarrollar los consumidores como colaboradores de la producción y difusión de estas comunicaciones. La figura del prosumidor y su importante papel en las acciones de marketing viral han trazado nuevos caminos y oportunidades para desarrollar comunicaciones publicitarias que cuentan con el compromiso de los consumidores (Martí, Cabrera y Aldás 20I $2,336-7$ )

A raíz de esta cita, se puede deducir que es más fácil comprometerse o conectar con un contenido o mensaje que se ha ayudado a crear, que otro del que se es simplemente un receptor pasivo. En este aspecto, se trae a colación un ejemplo de publicidad de marca que por su sencillez e incluso inocencia, puede resultar muy ilustrativo para entender el lazo irrenunciable del consumidor con la creación de la marca y las campañas de comunicación de la empresa. 
El ejemplo en cuestión se refiere a la campaña de las galletas Tosta Rica, "Las Tosta Rica las dibujas tú", un concurso de dibujo donde nińos y niñas pueden enviar sus propuestas, sabiendo que los dibujos ganadores serán impresos en las famosas galletas. Un rasgo interesante de este caso es cómo el/la consumidor/a no solamente participa en la comunicación, sino que transforma tanto la marca como su producto tangible, en este caso, las galletas. Al imprimir su dibujo sobre la galleta, el sujeto está formando parte de la marca y a la inversa. Al fin y al cabo, ¿¿dónde acaba la marca y empieza la persona? Las fronteras no son rígidas y quizá ni tan siquiera existen, ya que al adquirir un producto o servicio, el/la consumidor/a se está apropiando de sus significados. Así pues, el/la consumidor/a tiene el poder de decisión, porque los intangibles que manejan las empresas y marcas se desarrollan en su mente, y la empresa se limita a adivinar ese pensamiento e intentar influir en él de buen grado. Como bien señala Joan Costa, la imagen es un intangible que se forma en la mente del público, por eso la empresa no puede incidir directamente sobre dicho activo, solamente lo puede intentar por medio de la comunicación y los valores (CosTA I999).

Por tanto, la figura del prosumer compone lo que se podría considerar una gran base de talentos que la empresa no puede desperdiciar ni ignorar. Un ejemplo claro de esta marea de influencia del público en la gestión de las marcas se ejemplifica en la proliferación de redes o plataformas en las que cada internauta puede acceder y compartir su opinión y/o experiencia sobre un producto o servicio concreto. En el caso del sector hotelero, existen ejemplos como Booking.com o TripAdvisor entre otros. Estas plataformas sirven de espacio de interacción entre consumidores/as, donde es posible "sharing information with friends and to a certain extent with the public ... that allows humans to stay in touch and to make new contacts" (Fuchs 20 I I, 292). Porque el criterio de los iguales es el que más puede ayudar a realizar la elección adecuada, cada vez más la gente, consciente de su poder de influencia, quiere compartir su opinión y esto es señal de que cada vez son más activos, saben cómo quieren las cosas, e invierten su tiempo en hacérselo saber a la empresa misma.

Como se puede observar, sería un error para las organizaciones empresariales dejar todo este saber desprovisto de atención, lo que implica que el mejor modo de gestionar la comunicación de cualquier tipo de organización es encontrarse en contacto directo y constante con los diferentes stakeholders o grupos de intereses, que hoy en día toman la forma de prosumers. Porque el establecimiento de un diálogo recíproco va a permitir no solamente que la empresa esté al tanto de los cambios que se dan en el entorno y que van a afectar a su producto, sino que le va a autorizar a beneficiarse, entendido en una vertiente mutua, de los conocimientos, intereses y aspiraciones de esta figura. Es decir, ¿quién conoce mejor a la marca que los/as consumidores/as? Nadie. 
Todos los conocimientos, experiencias y expectativas que conforman su relación con la marca, solamente pueden ser conocidos por ésta, desde el diálogo y la cesión de parte de su poder en este grupo. Y las nuevas posibilidades técnicas que brinda el espacio web, pueden ser adecuadas para acercar esos diálogos simétricos a una realidad cada vez más factible, que permita al mismo tiempo edificar conductas empresariales éticas.

\subsection{Consumo y ciudadania: el ange de voces criticas}

Los últimos acontecimientos políticos y económicos han hecho mella en el espíritu de la ciudadanía, transformando las relaciones de consumo y de otra índole. La creciente desconfianza que impregna las diferentes esferas sociales promueve la construcción de un/a consumidor/a que entiende el consumo como una actividad moral, y que demanda de las empresas una actitud ética y una comunicación veraz. Desde el punto de vista de las organizaciones empresariales, la tendencia debe ir encaminada a un cambio en la forma de entender la gestión de la información, un paso clave para ir hacia la integración de una gestión ética en las empresas.

De este modo, en los tiempos que corren las barreras que separaban la información privada de la empresa de aquella que estaban obligados a presentar públicamente, se han distorsionado. Y debido al auge de una ciudadanía crítica y activa, ahora no son solo las leyes las que demandan la publicidad de dicha información, sino que también lo reclama la sociedad civil. Y es que, los grupos de intereses son observadores que exigen la rendición de cuentas a la organización. En este aspecto, Epstein habla de cómo la transparencia en la gestión y la información de los avances de la empresa, puede convertirse en una ventaja competitiva, ya que permitirá que dichos grupos sean leales a la institución. Tradicionalmente la teoría económica clásica ha primado la información sobre los indicadores financieros, dejando de lado los no financieros, que puedan contribuir a la salud de la compañía. Sin embargo, en un contexto como el actual, esto no resulta suficiente, dicho autor pone de relieve la necesidad de reformular los principios comunicativos y de información de las empresas.

En un tiempo en que las personas ajenas a la empresa tienen más elección que nunca respecto a dónde invertir su capital, para quién trabajar, con quién asociarse, y dónde comprar bienes y servicios, muchos gerentes están ofreciendo más información a fin de hacer que estas personas se decidan por su compañía. Los gerentes están llegando a la conclusión de que no existen buenas razones para mantener ocultos los datos que indican el rendimiento empresarial (EPSTEIN y BIRCHARD 2OOI, 27) 
Atrás han quedado los tiempos de ocultar información y permitir acciones corruptas, las empresas que deseen conectar con este nuevo prosumidor/ a-ciudadano/a, como la autora le va a denominar aunando los dos rasgos principales vistos anteriormente, deberán mostrarse abiertas al diálogo. Para generar lealtad entre los grupos de intereses, se debe dejar atrás la cultura de la confidencialidad, que no hace más que alejar a la empresa de sus públicos, desestructurando las posibles relaciones fructíferas que podrían darse entre ellos. El paso de una comunicación unidireccional a otra con múltiples focos, cuyos centros de acción se encuentran dispersos y generan un fluir de ricas aportaciones, es una de las tendencias comunicativas que más fuerza está cogiendo. Atrás deben quedar las organizaciones autistas, porque actualmente "existe una división entre las empresas analógicas que están mal vistas y las de la sociedad digital, porque se adaptan mejor en términos de comunicación a las exigencias de esta sociedad, que son muy elevadas" (Moratalla 20 I 5). El público se decanta hacia aquellas empresas y marcas que le permiten expresarse, pero sobretodo, que atiendan a la realidad social y actúen éticamente, estableciendo canales de comunicación con múltiples focos.

Descubriremos que estos nuevos mensajes, más que depender del medio utilizado, dependen de la mentalidad que hay detrás, de una visión mucho más "adulta" del consumidor. Formas de comunicar que utilizan mecanismos de diálogo, participación, donde la utilidad de lo que la marca propone supera la mera imposición de un mensaje. No cambia el medio, cambia la forma de pensar en quién recibe el mensaje (CERIA 20I4, 194)

La figura del prosumidor/a-ciudadano/a aprende a interactuar con la organización a través del potencial revolucionario y transformador de las nuevas herramientas de comunicación. Sin embargo, no es el medio online el que cobra importancia, "sino la tecnología en sí como capacidad de revolucionar los procesos de interacción con el público, ... de meter literalmente el/la consumidor/a dentro del proceso, de modificar de forma sustancial la manera en la que concebimos la construcción de una marca desde la comunicación" (Ceria 20i4, 195). Toda empresa y marca que se resista a comprender este nuevo papel del consumidor/a como ciudadano/a, estará negando la realidad y actuando sin entender qué significa realmente atender a las exigencias de los stakeholders. La ciudadanía es a la vida política lo que los/as consumidores/ as a la económica, es decir, es el/la consumidor/a como ciudadano/a económico el que tiene el poder frente a los productores, frente al marketing y la publicidad. Por eso debe implicarse activamente en orientar el consumo hacia un modelo más responsable desarrollando conciencia de su poder, porque es 
quien decidirá si consume o no, o si apoya a una organización. También será responsable de desmontar las viejas prácticas comunicativas unidireccionales y de dudosa ética, para construir otras que pongan en el centro la ética y la transparencia.

Un ejemplo de este papel activo del prosumidor/a-ciudadano/a reside en las respuestas ciudadanas frente a la comunicación o publicidad que no se considera ética. $Y$ es que, se debe comprender que al hablar de público también se habla de ciudadanos y ciudadanas conscientes de las implicaciones sociales que subyacen a los discursos mediáticos. En esta línea, Feenstra analiza la monitorización publicitaria (FeENSTRA 20I3A) como un proceso político que permite al público responder frente a aquellos anuncios que consideran inmorales, mediante una atenta observación de la comunicación publicitaria. La contrapublicidad y el activismo mediático son parte de este proceso. El primer caso se refiere a la denuncia, de forma organizada y creativa, de las malas prácticas publicitarias, así como del propio modelo de consumo, mediante el uso del lenguaje publicitario de las marcas (FeEnstra 20i 4, 100). En el segundo caso, consumidores anónimos "denuncian posibles engaños publicitarios, o contestan anuncios que son considerados erróneos, falsos o inadecuados" (Feenstra 20 I4, 103). Se produce pues una eclosión de voces que pueden servir a la empresa para conocer las expectativas depositadas por parte del público en su actividad, y por tanto, en la medida en que se establezcan diálogos con dichas voces, se podrá fundamentar la legitimidad social de la organización. Lo importante es tomar conciencia de que los ciudadanos/as están empezando a adoptar "un papel social relevante cuando actúan como consumidores en busca de un fin que va más allá de las exigencias del propio consumo" (De Miguel 2013, 9).

Sin embargo, si bien es cierto el aumento en el surgimiento de voces críticas entre los propios consumidores, no debemos pasar por alto el ruido informativo al que estos deben enfrentarse en su día a día, y que puede acabar provocando en dicho público una distorsión de la realidad. Es decir, cabe tener en cuenta que el flujo de información ingente e inmanejable a que está expuesto el/la consumidor/a puede obstaculizar la formación de su voz crítica y sus posibilidades de influir en las empresas (ZhaO et al. 20I6; CHen et al. 20i6; Ariely 2000). Así, cuanto más crítico sea el consumidor con la selección informativa, más podrá cerciorarse la empresa de que su criterio es válido para juzgar la actividad empresarial con respecto a unos parámetros universales. En esta línea, algunas prácticas como el whistleblowing nos muestran que los sistemas de alertas y denuncias de irregularidades ético-legales perpetradas por las empresas pueden ser una nueva herramienta de gran efectividad para que los/as consumidores/as aprendan a incidir sobre dichas acciones nocivas (Calvo 20i6). 


\section{El restablecimiento de la CONFIANZA PERdida}

Con el estallido financiero del 2007, salieron a la luz las malas costumbres que habían arraigado en numerosas instituciones. En términos generales, las decisiones tomadas por agentes empresariales habían puesto por encima del bienestar social, los intereses egoístas de unos pocos, basándose en la premisa de un homo oeconomicus desprovisto de valores morales (CAlvo 20IOB). En el caso de Espańa, "a las malas prácticas financieras, a la falta de control de esas prácticas, a la corrupción política se unieron problemas como el de la construcción y, en el fondo de todo ello, malas costumbres, empecinadamente arraigadas" (Cortina 20I3, 21), las relaciones de confianza entre los agentes sociales y económicos se vieron rotas. En este sentido, no se debe olvidar que "la confianza en una empresa, en sus relaciones contractuales o en sus productos, guarda relación directa con las razones que tenemos para esperar un determinado comportamiento o resultado, con el cumplimiento de una serie de expectativas previamente depositadas en ella" (GARCÍA-MarZÁ 2004, 146). De este modo, las empresas no pueden obviar los procesos de cambio social que están ocurriendo, porque afectan a su rol y sus relaciones con la sociedad, así como tampoco pueden obviar el nuevo papel del/la prosumidor/a-ciudadano/a. La situación de desafección ciudadana con respecto a las entidades económicas y gubernamentales, tiene mucho que ver con el incumplimiento de las expectativas, ya que se ha puesto por encima del interés social el interés egoísta. La situación actual muestra que el cuento del autointerés y el individuo autónomo se ha mostrado como lo que siempre fue: falso.

És d'idiotes, d'idiotes racionals, com diu el mateix Sen, pensar que l'egoisme i l'interès propi fan funcionar per si mateixos els mercats. Sense aquest saber moral, sense la honestedat que comporta respectar els contractes; sense la cooperació i col-laboració necessàries per a la producció; sense la credibilitat del producte o marca, etc., no hi ha confiança. I sense confiança no hi ha mercat, només hi ha selva. Com conclou Sen, l'ètica empresarial es pot considerar com un dels actius productius més importants que una economia i una societat disposen (García-Marzí 2O I 2, 9)

Cuando aquel 15 de mayo de 2011, miles de ciudadanos/as salieron a ocupar plazas y calles, también lo hicieron como consumidores/as. La ciudadanía reveló su poder, mostrando indignación frente a vicios como la corrupción y el egoísmo, que estaban ocultos tras las prácticas de ciertas entidades y sus comunicaciones. Un ejemplo de la necesidad de cambios, tanto en la gestión como en la comunicación, dentro de este nuevo escenario, lo encontramos 
en el caso Bancaja, analizado por la consultora de comunicación Villafañe \& Asociados. En marzo del año 2011 Bancaja pasó a denominarse Bankia, nombre que se estableció como marca comercial. En estos momentos, "Bankia se había convertido en diana de todas las críticas que suscitaba el sector financiero por parte de una ciudadanía desencantada que comenzó a desconfiar de todo y todos" (Sotillo y Rubiños 2014, 67). La marca Bankia, con poco tiempo de vida, acumulaba una gran desconfianza de sus clientes, lo que la había convertido en un "activo tóxico". Se precisaba con urgencia una estrategia para recuperar la confianza perdida. En el contexto del $15 \mathrm{M}$ la entidad se planteó un nuevo cambio de marca, ante lo que la consultora se negó, alegando que no se conseguiría recuperar la confianza del público planteando una estrategia lampedusiana, que se basa en cambiar algo ínfimo, para que realmente nada cambie. Se precisaba pues de cambios más profundos, que atañen a la raíz misma de las acciones de empresas y organizaciones, y en cómo se relacionan con el público, ambos procesos a largo plazo.

Y es que utilizar la comunicación de forma estratégica ha sido en parte uno de los grandes errores cometidos por empresas y otras instituciones, pensar que con una comunicación falsa podían ganarse al público y disfrazar la inmoralidad de sus malas decisiones, en el caso de que se diesen, ha ido generando cada vez más desconfianza en el público. Porque el/la consumidor/a actual ha dejado atrás su minoría de edad, y es capaz de distinguir un engaño cuando lo ve, porque ha sido enseñado a través de numerosas campañas diseñadas para hacer un lavado de cara de diferentes marcas. Al igual ha ocurrido con la ética en la empresa, que ha sido utilizada como cosmética para tapar malas prácticas (LuQue et al. 2016; Gil, 20I7; Pérez y Betancur, 20I7). Sin embargo, no hay maquillaje lo bastante fuerte como para tapar los vicios arraigados, y menos cuando emerge la figura del/la prosumidor/a-ciudadano/a, que sabe cómo influir en las empresas a través de sus propios contenidos, al mismo tiempo que identifica los riesgos sociales de sus actuaciones. Atendiendo a esta realidad, se podría decir que las empresas parecen haber olvidado que no son organizaciones neutras, sino que se encuentran insertas en el ámbito social y que por tanto, disponen de "capacidad para dar respuesta a los problemas de la sociedad" (García Echevarría I982, 28). Dicho desajuste entre el sentido social de la empresa y la nula atención que presta hacia sus responsabilidades con para los/ as afectados/as de sus acciones, provoca que hoy en día exista la necesidad de recordar que la confianza es un recurso moral clave para el funcionamiento de las organizaciones. Se ha de reconocer que las relaciones empresa-sociedad, se basan en conjuntos de expectativas, que conforman a su vez las relaciones de confianza en el entramado social: 
La confianza, entendida como relación social, tiene dos polos: el del sujeto que confía (truster) y el del depositario de la confianza (trusted). El sujeto ejecuta la acción de confiar a partir de un universo de conocimientos o creencias que le permiten tener un conjunto de expectativas ciertas sobre su relación con el objeto de su confianza. Confiar significa apostar, mantener expectativas, tener esperanza en que los referentes utilizados son ciertos, esto es, que corresponden realmente a las características del depositario. ... Es por esto que las relaciones de confianza involucran el riesgo irreductible de ser defraudado, y una desventaja: la vulnerabilidad (LuJÁn Ponce I999, 39-40)

Así pues, la vulnerabilidad contiene una doble vía, en el sentido de que la empresa cuenta con la legitimidad que le otorga la sociedad, sin embargo, al haber defraudado las expectativas que ésta disponía en su actuación, ha perdido su papel legítimo. El sociólogo Bernard Barber describe la confianza como "a generalized expectancy of good behaviour on the part of others over whom we have no control (...) has the general function of social ordering, of providing cognitive and moral expectation maps for actors and systems as they continuously interact” (BARBER I983, 19). De alguna manera, la confianza permite que se den por sentadas ciertas premisas de comportamiento, el actuar sobre la idea de que no nos defraudarán y no defraudaremos. Al mismo tiempo, estas razones permiten actuar en el escenario social, al igual que confiamos que una institución interactúe con los distintos grupos sociales en base a unos principios morales concretos, derivados de su papel social. A partir de las ideas de Barber, García-Marzá entiende que la confianza tiene bases racionales:

We can therefore say that trust has a rational base, or that it is supported by reasons. This cognitive base cannot "guarantee" the result of the action, but it does allow us to assume the risk involved in trusting a person, organization or product. In other words, it enables us to link our intentions with the possible results we expect (GARCÍA-MARZÁ 2005, 210)

Las relaciones de confianza no se basan en creencias o esperanzas ciegas depositadas en algo incierto que se desea que acontezca, sino en un juego recíproco de expectativas y obligaciones. Expectativas que se depositan en la actuación de la organización, y obligaciones que se contraen en función de lo que ese otro va a esperar de nosotros. En la medida en que se cumpla este círculo, podremos contar con la confianza de los demás, ya que habremos cumplido nuestro papel. En el ámbito empresarial, la confianza es un recurso que permite a la empresa gestionar su relación con los grupos de intereses con menores costes, y de forma legítima, ya que reduce los costes de coordinación y tran- 
sacción (GARCÍA ECHEVARRÍA I982, 19), al fomentar una cooperación social a través del contrato moral propuesto por García-Marzá. Por consiguiente, para restablecer la confianza perdida y la legitimidad, se deben reconsiderar las bases de la relación social de la empresa con los grupos sociales desde la noción de contrato moral.

Cuando habla de contrato moral, García-Marzá se refiere a un "acuerdo racional entre todas las partes implicadas y/o afectadas por la actividad empresarial" (GARCíA-MARZÁ 2004, 160). Este contrato permite recoger la reciprocidad, ya que a partir de él se reconoce el hecho de que existe entre la empresa y sus grupos de intereses un juego de expectativas recíprocas. Siguiendo las bases de la ética discursiva, los diálogos que subyacen a dicho contrato, se han de dar en condiciones de igualdad y en simetría de participación para todos los interlocutores válidos, hecho que implica que a diferencia del contrato social, el contrato moral no constituye en sí un hecho, sino una instancia crítica, una idea regulativa de las condiciones. Así, el contrato moral difiere del social en cuatro aspectos: las partes contratantes, el contenido, las condiciones y el carácter (GARCíA-MARZÁ 2004, 161-2). En cuanto a las partes contratantes, el contrato moral obliga a llegar al acuerdo entre todos los grupos afectados por la actividad de la empresa. Respecto al contenido, el contrato moral rompe el individualismo propio del contrato social, ya que se tiene en consideración desde el principio que el sujeto no es solamente un individuo, sino una parte con intereses en juego, en confluencia con los intereses de los demás. Las condiciones se refieren a la igualdad y la simetría, cuya legitimidad viene respaldada por la posibilidad de participación de todos los involucrados. Y por último, el carácter del contrato moral es el de un principio crítico que permite reconstruir las condiciones de posibilidad para la realización de acuerdos fácticos.

En resumen, el principio del diálogo en búsqueda del acuerdo entre las partes afectadas por la actividad empresarial, no describe un contrato social, sino que define un contrato moral basado en la plena ausencia de coacción entre los participantes. Se trata de diálogos en los que existe la posibilidad de comunicación, donde están incluidos todos los afectados por la actividad empresarial, donde se incluiría como no, la nueva figura del/la prosumidor/aciudadano/a que se ha ido tratando a lo largo del presente artículo de investigación. Dichos diálogos subyacentes a la ética empresarial propuesta, basada en un contrato moral, permite afirmar que sin confianza no hay economía, no hay progreso social, y que en la ética empresarial y el reconocimiento de la confianza como recurso moral están las claves para restituir el papel social de las empresas. A partir de la noción del contrato moral, se crean las condiciones de posibilidad para la construcción de relaciones sanas entre empresas y sociedad, al mismo tiempo que se consiguen "empresas virtuosas cuyo funcionamiento 
se estructura a partir de la reciprocidad, la cooperación y la confianza" (GARCíA-MARZÁ 2004, 58), éste es el carácter que deberían haber tenido siempre las empresas, evitando la funesta situación social actual. Dicha cooperación también permitiría afianzar los saberes acumulados por los/as prosumidores/ as-ciudadanos/as, aportando voces motivadoras y críticas a la práctica empresarial y sus comunicaciones.

\section{Conclusiones}

Actuar como organización en un contexto eminentemente globalizado es una tarea de gran envergadura, ya que la empresa debe ser capaz de ajustar las respuestas que efectúa frente a las diferentes demandas de los grupos de interés, a las circunstancias cambiantes de los contextos en que desarrolla su actividad. Una de las claves del reto a tratar reside en el reconocimiento de que las instituciones sociales, entre ellas las económicas, tienen que cumplir las expectativas depositadas en ellas por parte del público para poder generar y mantener su confianza. Una confianza que se halla en la dimensión moral manifiesta a través de bases racionales en los diálogos. Y esto implica llevar a cabo la integración de la perspectiva ética dentro de la estructura empresarial. Hecho que solo será posible si se reconoce antes a la empresa como una institución social y se admite que es necesario gestionar sus recursos morales para conseguir beneficios sociales.

En este aspecto, generar valor social, comportarse éticamente, pero sobre todo, saber comunicárselo de forma veraz al público, va a permitir a la larga construir una buena reputación, y resulta de gran interés señalar que "las empresas reputadas tienen un halo de credibilidad que puede resultar decisivo a la hora de afrontar informativamente los efectos de una crisis" (Villafañe 2004, 86). Pero dicha credibilidad debe encontrar razones de peso para sustentarse, y dichas razones van de la mano de las demandas que realizan los/as consumidores/as como parte de la ciudadanía. Porque una organización empresarial no puede hacer oídos sordos a las voces que emergen de su entorno, porque no puede actuar de espaldas a las exigencias sociales que le lanza el/ la prosumidor/a ciudadano/a. Es tiempo de actuar y comunicar éticamente. Porque de ningún otro modo se podrá generar confianza, y una sociedad sin confianza no es lugar para la convivencia de seres humanos ni de instituciones. 


\section{BIBLIOGRAFÍA}

Alvarado, A.; Bigné, E. y Currás, R. 2009, "Perspectivas teóricas usadas para el estudio de la Responsabilidad Social Empresarial en el marketing: una aproximación a la complementariedad de sus racionalidades", XIII Congreso Internacional de Investigación en Ciencias Administrativas La administración frente a la globalización: Gobernabilidad y desarrollo, 5, 6, 7 y 8 de mayo de 2009: 1-29.

Álvaro, F.-M. 201 3, "Democracia acelerada y periodismo bajo sospecha”, adComunica. Revista Cientifica de Estrategias, Tendencias e Innovación en Comunicación, 6: 225-8. http://dx.doi.org/10.6035/2174-0992.2013.6.13

Andreu-Sánchez, C. y Martín-Pascual, M. A. 20 I4, "La educación audiovisual y la creación de prosumidores mediáticos. Estudio de caso", adComunica: Revista Cientifica de Estrategias, Tendencias e Innovación en Comunicación, 7: 131-47. http://dx.doi.org/10.6035/2174-0992.2014.7.8

Ariely, D. 2000, "Controlling the Information Flow: Effects on Consumers' Decision Making and Preferences", Journal of Consumer Research, 27 (2): 233-48.

BArber, B. I983, The logic and limits of trust, New Brunswick: Rutgers University Press.

Calvo, P. 20 ioa, "La Participación Dialógica como Herramienta de Gestión Responsable”, en M. A. Arráez y P. Francés (ed.), Ética y Responsabilidad ante la Crisis, Granada: Sidner: 261-82.

Calvo, P. 2огов, “¿Homo economicus u homo reciprocans? Contribución de la ética y la neuroeconomía al principio de reciprocidad", en A. Sierra y Y. Romero (ed.), Actas del V Congreso Internacional de la Sociedad Académica de Filosofía: razón, crisis y utopia, Tenerife: Universidad de la Laguna: 97-110.

Calvo, P. 201 3, "Fundamentos de la economía civil para el diseño de las organizaciones", Revista Internacional de Organizaciones, 10: 65-84.

Calvo, P. 20i6, "Whistleblowing ante la miseria moral de insituciones y organizaciones", en Meseguer, J. V. y Avilés, M. (dir.), Empresas, Derechos Humanos y RSC, Pamplona: Editorial Aranzadi: 135-53.

Ceria, U. 20 I4, "Nada volverá a ser lo mismo entre nosotros. Agencias y anunciantes, medios y mensajes, marcas y consumidores: o se reinventa la relación, o nos separamos para siempre", adComunica. Revista Cientifica de Estrategias, Tendencias e Innovación en Comunicación, 7: 193-6. http://dx.doi. org/10.6035/2174-0992.2014.7.11

Chen, J.; Teng, L.; Yu, Y. y Yu, X. 20 I6, "The effect of online information sources on purchase intentions between consumers with high and low susceptibility to informational influence", Journal of Business Research, 69 (2): 467-75.

Conill, J. 2006, Horizontes de economía ética, Madrid: Tecnos. 
Cortina, A. I997, "Introducción”, en A. Argandoña (ed.), Ética y empresa: una visión multidisciplinar, Madrid: Fundación Argentaria: 9-26.

Cortina, A. 2003, Construir confianza: ética de la empresa en la sociedad de la información y las comunicaciones, Madrid: Trotta.

Cortina, A. 2005 , "Ética de la empresa: no solo responsabilidad social", en Ética de la empresa: hacia un nuevo orden global, XIV Seminario Permanente de Ética Económica y Empresarial (2004-2005), Valencia: Fundación ÉTNOR: 7-18.

Cortina, A. 201 3, ¿Para qué sirve realmente la ética?, Barcelona: Paidós.

Costa, J. I999, La comunicación en acción. Informe sobre la nueva cultura de gestión, Barcelona: Paidós.

Del Fresno, M. 2012, El consumidor social. Reputación online y social media, Barcelona: Editorial UOC.

De Miguel, I. 20I3, "Recuperando el control sobre la economía: el consumo como herramienta de poder", Dilemata, 13: 1-32.

Donaldson, T. I982, Corporations and Morality, Englewood Cliff, NJ: Prentice Hall.

Donaldson, T. y Dunfee, T. W. I994, "Toward a unified conception of business ethics: integrative social contracts theory", The Academy of Management Review, 19 (2): 252-84.

Donaldson, T. y Dunfee, T. W. I999, "When ethics travel: The promise and peril of global business ethics", California Management Review, 41 (4): 45-63.

Epstein, M. y Birchard, B. 200 i, La empresa honesta. Cómo convertir la responsabilidad corporativa en una ventaja competitiva, Barcelona: Paidós.

Feenstra, R. A. 2013A, "La monitorización de la publicidad en la era digital: un reto para la ética”, Cuadernos.info, 32: 47-58. http://dx.doi.org/10.7764/ cdi.32.477

Feenstra, R. A. 20г зв, "Una reflexión sobre la Democracia Monitorizada: potencialidades y límites", Foro Interno, 13: 139-60. http://dx.doi.org/10.5209/ rev_FOIN.2013.v13.43088

Feenstra, R. A. 20I4, Ética de la publicidad. Retos en la era digital, Madrid: Dykinson.

Feenstra, R. A.; Tormey, S.; Casero-Ripollés, A. y Keane, J. 20 i6, La reconfiguración de la democracia: el laboratorio politico español, Granada: Editorial Comares.

Freeman, R. E. I984, Strategic Management. A Stakeholder Approach, Boston: Pitman.

Fuchs, C. 20II, "Web 2.0, Prosumption, and Surveillance", Surveillance \& Society, 8 (3): 288-309.

García Echevarría, S. I982, Responsabilidad social y balance social de la empresa, Madrid: Fundación Mapfre. 
García-Marzá, D. 2004, Ética empresarial: del diálogo a la confianza, Madrid: Trotta.

García-Marzá, D. 2005, "Trust and Dialogue: Theoretical Approaches to Ethics Auditing", Journal of Business Ethics, 57 (3): 209-19. http://dx.doi.org/ 10.1007/s10551-004-8202-7

García-Marzá, D. 20 I 2, Ettica o crisi. La distribució de la responsabilitat, Castelló de la Plana: Servei de Comunicació i Publicacions.

GIL, G. 2017, "Análisis Discursivo del relato empresarial sobre Responsabilidad Social Corporativa. Coordenadas narrativas y prácticas discursivas", Recerca, Revista de Pensament i Anàlisi, 20: 127-56. doi: http://dx.doi.org/10.6035/ Recerca.2017.20.7

GonzÁlez Esteban, E. 2007, "La teoría de los stakeholders. Un puente para el desarrollo práctico de la ética empresarial y de la responsabilidad social corporativa", Veritas, 2 (17): 205-24.

González Esteban, E. 201 2, "El modelo de empresa plural desde el enfoque de los skateholders", Debats, 116: 71-80.

González Esteban, E. y García-MarzÁ, D. 2006, "La Responsabilidad Social Empresarial (RSE) en Europa: la apuesta por un nuevo modelo de empresa. Una revisión crítica desde la ética empresarial", Recerca, Revista de Pensament $i$ Anàlisi, 6: 157-170. http://dx.doi.org/10.6035/Recerca

Luján, N. I999, La construcción de confianza política, México DF: Instituto Federal Electoral.

Luque, A.; Hernández, J. y De Pablos, C. 20i6, "Debilidades dentro de los procesos de mundialización textil y relación con la RSE a través de un análisis DELPHI: ética o estética", Recerca, Revista de Pensament i Anàlisi, 19: 35-71. doi: http://dx.doi.org/10.6035/Recerca.2016.19.3

Martí, J.; Cabrera, Y. y Aldás, J. 20 2, "La publicidad actual: retos y oportunidades, Pensar la publicidad, 6 (2), 327-43. http://dx.doi.org/10.5209/ rev_PEPU.2012.v6.n2.41219

McLuhan, M. y Nevitt, B. 1972, Take Today: The Executive as Dropout, Nueva York: Harcourt Brace Jovanovich.

Medina-Aguerrebere, P. 2013, Marca y comunicación empresarial, Barcelona: Editorial UOC.

Moratalla, M. 2015 (enero 27), "El 'consumidor rebelde' que rechaza a las empresas: es el fenómeno de Podemos aplicado al mercado", Vozpopuli.com. Retrieved from http://vozpopuli.com/economia-y-finanzas/56506-el-consumidor-rebelde-que-rechaza-a-las-empresas-es-el-fenomeno-de-podemos-aplicado-al-mercado

Pérez, M. y Betancur, A. 20 I7, "Gestión del sector minero en el ámbito colombiano y su relación entre el accionar gubernamental y empresarial”, Recerca, 
Revista de Pensament i Anàlisi, 20: 157-84. doi: http://dx.doi.org/10.6035/ Recerca.2017.20.8

Querol, V. A. 20 I I, Las generaciones que llegaron tarde. Análisis de las prácticas sociales de los mayores en el ciberespacio, Barcelona: Editorial UOC.

Ritzer, G. y Jurgenson, N. 2oio, "Production, Consumption, Prosumption: The nature of capitalism in the age of the digital 'prosumer', Journal of Consumer Culture, 10 (1): 13-36. http://dx.doi.org/10.1177/1469540509354673

Sotillo, S. y Rubiños, M. 20 4 4, "Del Caso Bankia al Case Bankia”, en J. VillaFAN̂́ (ed.), La recuperación de la confianza, Barcelona: Gedisa: 65-84.

Tofrler, A. 1980, The Third Wave, Nueva York: William Morrow.

VILlAfañe, J. 2004, La buena reputación. Claves del valor integible de las empresas, Madrid: Pirámide.

Zhao, Q.; Huang, Z.; Harper, Maxwell, F.; Terveen, L. y Konstan, J. A. 2016, "Precision CrowdSourcing: Closing the Loop to Turn Information Consumers into Information Contributors", Proceedings of the 19th ACM Conference on Computer-Supported Cooperative \& Social Computing, San Francisco, California, USA-February 27 - March 02: 1615-25. 